\title{
Characteristics of the Hydrogen Absorption by $\mathrm{Sm}_{2} \mathrm{Fe}_{17}$
}

\section{$S m_{2} F e_{17}$ 合金の水素吸収特性}

\author{
Taro KIYOKAWA, Mutsuo ISHII, Kazuki KINOSHITA, Yoshihito MATSUMURA and Hirohisa UCHIDA \\ Department of Applied Physics, Faculty of Engineering, Tokai University \\ 1117, Kita-Kaname, Hiratsuka, Kanagawa 259-12, JAPAN \\ Tel. 81-463-58-1211(Ex.4136) Fax. 81-463-58-9461 \\ E-mail.30ap1219@keyaki.cc.u-tokai.ac.jp \\ ( Accepted for publication 8 November 1996 ) \\ The characteristics of the hydrogen absorption by $\mathrm{Sm}_{2} \mathrm{Fe}_{17}$ were investigated with \\ respect to equilibrium and kinetics properties. The measurd pressure-composition- \\ isotherms showed no pressure plateau, indicating the $\mathrm{Sm}_{2} \mathrm{Fe}_{17}$ forms only the hydrogen \\ solid solution phase at the temperature below $773 \mathrm{~K}$. In addition, the isotherms \\ suggest that $\mathrm{Sm}_{2} \mathrm{~F}^{\mathrm{e}} \mathrm{e}_{17}$ absorbs hydrogen in hydrogen concentrations up to $\mathrm{H} / \mathrm{Sm}_{2} \mathrm{Fe}_{17}=5.0$. \\ The reaction kinetics of hydrogen absorption revealed that the initial reaction rate \\ was controlled by the dissociation of $\mathrm{H}_{2}$ molecules on the surface.
}

Key words; $\mathrm{Sm}_{2} \mathrm{Fe}_{17} \mathrm{~N}_{\mathrm{x}}$, Nitromagnetics, Rare earth

\section{I . Introduction}

ポスト $\mathrm{Nd}_{2} \mathrm{Fe}_{14} \mathrm{~B}$ 磁不として注目されている $\mathrm{Sm}_{2}$ $\mathrm{Fe}_{1} 7 \mathrm{~N}_{3}$ 磁石は、その工業生産へ向けての難題が未 だ残されたままである。そのひとつに、 $\mathrm{Sm}_{2} \mathrm{Fe}_{1} 7$ 合金の純坴素による窒化速度の遅さがある。そこ で窒化速度を早めるため、アンモニアガスやアン モニア一水素混合ガス、窒素一水素混合ガス、水 素化前処理後の空化 ${ }^{1}$ よる方法がとられているが、 この場合窒素の吸収量も増大する傾向がある ${ }^{2,3}$ 。 これらの反応機構には依然不明な点が多く、詳細 なデー夕は出ていない。そこで、 $\mathrm{Sm}_{2} \mathrm{Fe}_{1} 7$ 合金と 水素との反忍特性について基本的知見を得るため、 $\mathrm{Sm}_{2} \mathrm{Fe}_{17}-\mathrm{H}$ 系のP(圧力)-C(組成)-T(温度)特性及び 水素吸収速度について测定を行った。

\section{Experimental details}

アーク溶解により作製した $\mathrm{Sm}_{2} \mathrm{Fe}_{1} 7$ 合金を、 $\operatorname{Ar}$ 雾囲気中 $1373 \mathrm{~K} に て 6 \mathrm{~h}$ の均質化処理を施した。 化学量論組成及び構造の確認はICP,XRDで行った。 それをグローブボックス内で乳錰により粉砕し、 粒径38〜75 $\mu \mathrm{m}$ にふるい分けて試料とした。実験に
は高圧ジーベルツ装置 (到達真空度 $8 \times 10^{-4} \mathrm{~Pa}$, 真空 リークレート $\left.6 \times 10^{-10} \mathrm{~Pa} \cdot \mathrm{m}^{3} \cdot \mathrm{s}^{-1}\right) 、 7 \mathrm{~N}-\mathrm{H}_{2} \mathrm{Jj}$ ス を用い、測定は水素圧力約 $10^{3} \sim 2 \times 10^{6} \mathrm{~Pa}$ 、反応温 度473〜673K及び室温にて行った。水素吸収量は体 積测定法により測定した。

III. Results and discussion

测定值及び Lacher model を用いて算出した等温 線をFig. 1に示す。測定範囲内では明確なプラトー 領域が見られないことから、 $\mathrm{Sm}_{2} \mathrm{Fe}_{17}-\mathrm{H}$ 系は水素 化物を形成せず、固溶体として水素を吸収するも のと考えられる。また計算結果より測定範囲外の ごく低温においても水素化物相は形成されないも のと推测される。

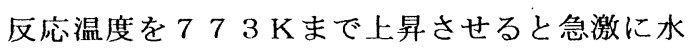
素を吸収し、测定後XRD分析を行った結果、熱分 解を起こしていることを確認した。

Figure2はXRD测定結果であるが、水素を吸収す るに従ってピークがシフトし格子が膨張している ことがわかる。a軸、c軸の格子定数の変化をあらわ した図Fig.3はa軸が単調增加、c軸は [H]/ 
$\left[\mathrm{Sm}_{2} \mathrm{Fe}_{17}\right]=0 \rightarrow 3$ までが収縮、 $[\mathrm{H}] /\left[\mathrm{Sm}_{2} \mathrm{Fe}_{17}\right]$ $=3 \rightarrow 5$ までが膨張という特罪な性藓であることが見 いだされた。

水素吸収速度曲線より求めた初期吸収速度 $\mathbf{v}$ と印 加圧力 $\mathrm{P}$ との関係をFig.4にホす。これより関係式 $\mathrm{v} \propto \mathrm{P}^{\mathrm{n}}(\mathrm{n}=0 \sim 1)$ において $\mathrm{n} \fallingdotseq 1$ となり、反応の律速は 合金表面における水素分子の解離律速になってい るものと推測される。

初期吸収速度 $\mathrm{v}$ と測定温度 $\mathrm{T}$ の関係より求女た Arrhenius plotより見かけの活性化エネルギーは $4.0 \pm 0.2[\mathrm{k} \mathrm{J} / \mathrm{mol} 1 \mathrm{H} 2]$ となった。この值は $\mathrm{H}_{2}$ の解離エネルギー406.6 [ $\left.\mathrm{k} \mathrm{J} / \mathrm{mo} 1 \mathrm{H} 2\right]$ と比 べとても低く、要因は $\mathrm{Sm}_{2} \mathrm{Fe}_{17}$ 合金上における $\mathrm{H}_{2}$ の

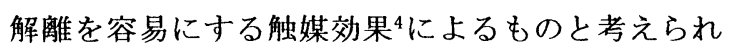
る。

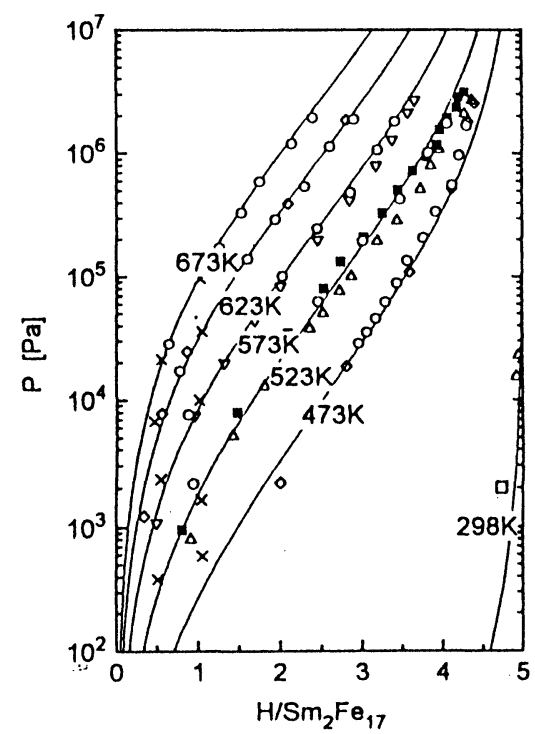

FIG.1 Pressure-Composition-isotherms for the $\mathrm{Sm}_{2} \mathrm{Fe}_{17}-\mathrm{H}$ system.

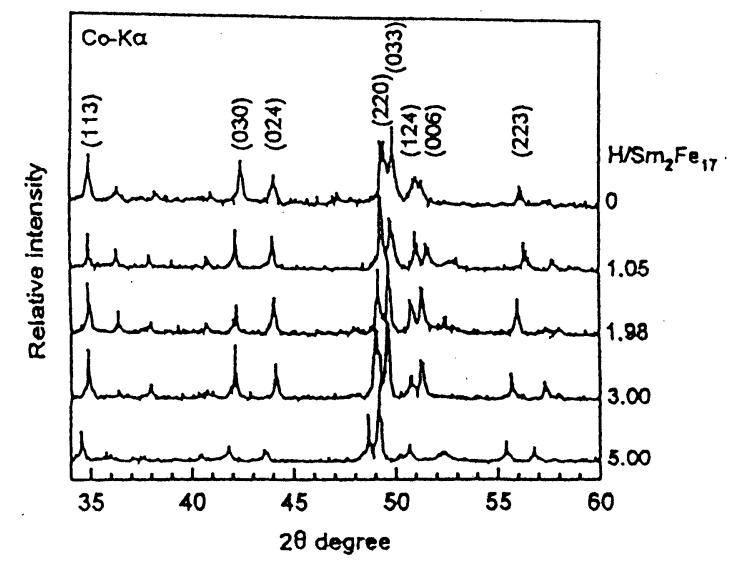

FIG.2 X-ray diffraction patterns of $\mathrm{Sm}_{2} \mathrm{Fe}_{17} \mathrm{Hx}$.

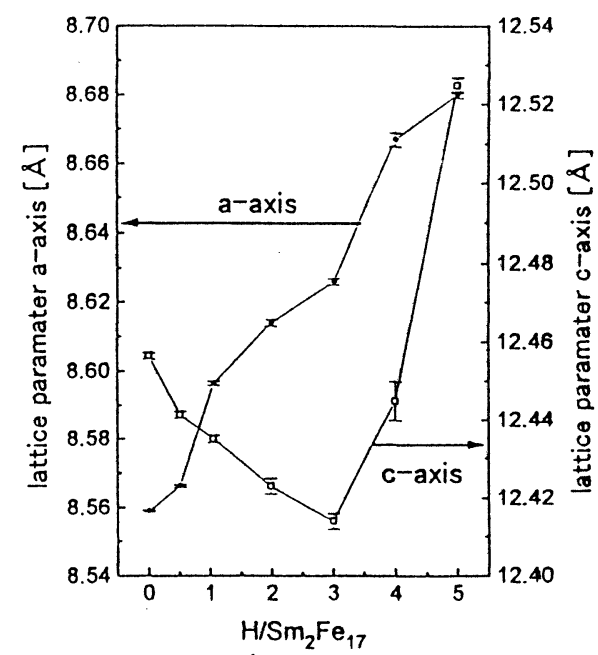

FIG. 3 Chenges in the lattice parameters of $\mathrm{Sm}_{2} \mathrm{Fe}_{17} \mathrm{Hx}_{\mathrm{x}}$ as function of $\mathrm{H}$ concentration.

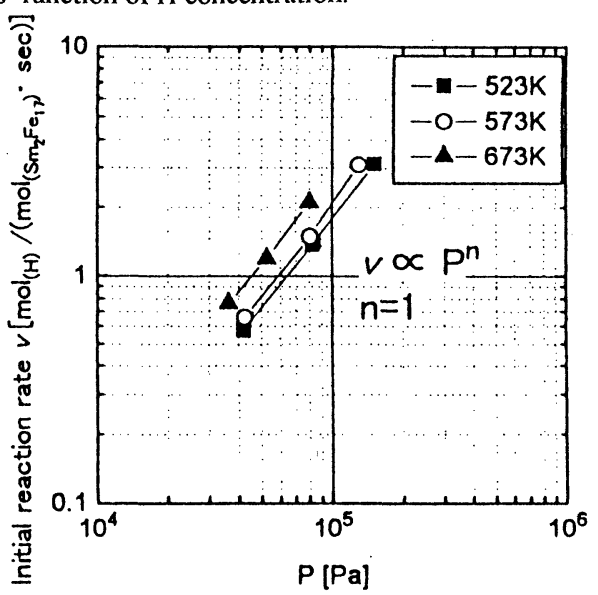

FIG.4 Dependence of the initial reaction rate $v$

on the initial pressure $P$.

【謝辞】本研究は東海大学総合研究機構 「エネルギー材料」プロジェクトの研究とし て行われた。

\section{References}

1.H.Uchida, H.H.Uchida, T.Yanagisawa, H.Kaneko, U.Koike,

K.Kamada, Y.Matsumura, T.Noguchi

J.Alloys and Compounds, 184(1992)L5-L8

2.V.Koeninger, H.H.Uchida, H.Uchida,

J.Alloys and Compounds,222(1995)117-122

3.U.Koike, K.Kamada, H.Uchida, V.Koeninger, Y.Matsumura, H.H.Uchida, T.Kurino, H.Kaneko

Proc. 12th Int.Workshop on RE Magnet and Their Applications, Canberra,(1992)237-248

4.H.Uchida,K.Ishikawa,T.Suzuki, T.Inoue, H.H.Uchida, J.Alloys and Compounds,222(1995)153-159

'96 SAS Intelligent Symposium 